Friederike D. Rass

\title{
Die Suche nach Wahrheit im Horizont fragmentarischer Existenzialität
}

Eine Studie über den Sinn der Frage nach »Gott« in der Gegenwart in Auseinandersetzung mit Gianni Vattimo, John D. Caputo und Jean-Luc Nancy

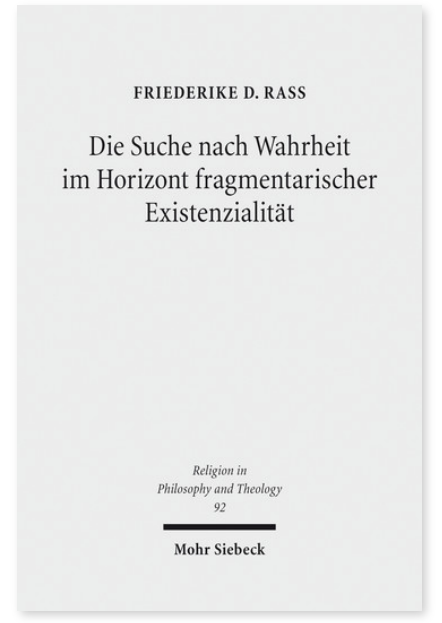

2017. XIV, 277 Seiten. RPT 92

ISBN 978-3-16-155542-8

DOI 10.1628/978-3-16-155542-8

eBook PDF $69,00 €$

ISBN 978-3-16-155366-0

fadengeheftete Broschur 69,00€
Die Suche nach der »einen Wahrheit« scheint im plural geprägten Horizont der Gegenwart ebenso überflüssig oder aber problematisch geworden zu sein, wie die Rede von dem einen Gott als Grund aller Wirklichkeit. Dennoch geben wir die Suche nicht auf, und auch das Wort »Gott« polarisiert weiterhin, sei es gesellschaftlich, wie auch in der Theologie und Philosophie. Wie ein Weg jenseits eines resignativen Rückzugs auf relativistische oder aber fundamentalistische Positionen aussehen kann, der diese Spannungslage für eine Neuorientierung nutzt, zeigt Friederike D. Rass in diesem Buch auf. Dabei werden sich gerade die vermeintlich vergebliche Suche nach der einen Wahrheit sowie die immer wieder neu zu stellende Frage nach der Bedeutung des Wortes »Gott« als wesentliche Wegweiser für ein verantwortliches Handeln in der Gegenwart erweisen.

Friederike D. Rass Geboren 1985; Studium der Ev. Theologie, Philosophie und Politikwissenschaften; 2015 Promotion; seit 2016 Wissenschaftliche Beraterin in der Abteilung für Internationale Forschungs- und Innovationszusammenarbeit des Staatssekretariats für Bildung, Forschung und Innovation in Bern.

Jetzt bestellen:

https://mohrsiebeck.com/buch/die-suche-nach-wahrheit-im-horizont-fragmentarischer-existenzialitaet-9783161555428? no_cache=1

order@mohrsiebeck.com

Telefon: +49 (0)7071-923-17

Telefax: +49 (0)7071-51104 